\title{
Green waste/ wood pellets pyrolysis in a pilot-scale rotary kiln: effect of temperature on product distribution and characteristics
}

\author{
Tchini Séverin TANOH, Amina AIT OUMEZIANE, Jérôme LEMONON, Francisco \\ Javier ESCUDERO SANZ゙, SyIvain SALVADOR
}

\author{
Université de Toulouse, IMT Mines Albi, UMR CNRS 5302, Centre RAPSODEE, \\ Campus Jarlard, F-81013 Albi, Cedex 09, France.
}

Keywords: Garden green waste, Pyrolysis, High-temperature, Products characterization

\begin{abstract}
In this study, a pilot-scale rotary kiln was used to perform the pyrolysis of garden green waste. The results are compared to wood pellets (a mixture of oak and beech sawdust). Both samples have similar organic composition and energy content except for ash content which is around three times higher in the case of green waste. Pyrolysis tests were performed at different temperatures ranging from 700 to $900^{\circ} \mathrm{C}$. The study of the products yields as a function of temperature showed that above $700^{\circ} \mathrm{C}$, volatile matter (gas and bio-oil) yields were higher than 80 wt.\% and syngas $\left(\mathrm{CO}+\mathrm{H}_{2}\right)$ concentration was higher than 59 mol.\%. On the other hand, the char yield was below 20 wt. \% with an HHV of $29 \mathrm{MJ} / \mathrm{kg}$ and an $80 \%$ carbon content. Tar quantitative gas chromatography/mass spectrometry (GC/MS) analysis showed the predominance of benzene and naphthalene. Hence, this work revealed and validated the relevance of green waste thermochemical conversion for syngas production. In addition, this investigation can support the optimization of operating parameters and energy efficiency of a two-staged gasification process where pyrolysis is a decisive initial step.
\end{abstract}




\section{Introduction}

Syngas $\left(\mathrm{CO}, \mathrm{H}_{2}, \mathrm{CO}_{2} \ldots\right)$ production via thermochemical conversion of biomass using processes such as pyrolysis and gasification has known a significant growth recently. The produced syngas can be converted into fuels like methane which can largely contribute to conventional energies substitution and climate change mitigation. However, the major problem encountered during pyrolysis and gasification processes is tar formation, which alters the quality of the producer gas and limits its use. Hence, tar removal and the increase of gaseous products yield from biomass are serious challenges. The two-stage combined pyrolysis-gasification appears to be effective for thermochemical biomass conversion producing an important gas yield, low tar contents and high biomass conversion rates ${ }^{1,2}$. In a combined pyrolysis-gasification process, biomass is pyrolyzed in the first stage and the pyrolysis gases (volatile products) are gasified or reformed in the second one $\mathrm{e}^{3,4}$. Therefore, in such a coupled process, pyrolysis is a crucial initial step. It is a process in which the biomass is thermally converted, in the absence of additional external oxygen, into bio-oil, gas and char. The pyrolysis products yield and quality vary as a function of conditions which are linked to the reactor, biomass types and characteristics as well as the operating parameters namely, temperature, pressure, heating rate, residence time, etc... ${ }^{5-7}$. Among the process parameters which affect the pyrolysis products, the temperature is a key one because it influences both quantity ${ }^{8}$ and quality of the products 9,10 . It is possible to maximise the product yield of one or two products as a function of the temperature. Several researchers have studied the influence of temperature on pyrolytic products of biomass using various reactors ${ }^{11-13}$ because the level of heat and mass transfer depends strongly on the reactor type. Aside from the commonly used ones such as tubular reactors, screw reactors, fixed-bed and fluidized-bed reactors, rotary kilns were also used for the pyrolysis of diverse biomass ${ }^{14,15}$. 
However, studies reporting on wood and green waste at high-temperature pyrolysis in a pilotscale rotary kiln in order to maximize volatile matter yield with detailed characterization of gas, tar and char composition are really scarce.

Li et a $1^{16}$ evaluated the influence of temperature $\left(550-850^{\circ} \mathrm{C}\right)$ on pyrolysis products of wood in a laboratory-scale rotary kiln. This study gave the product yields of wood pyrolysis. However, their investigations did not include gas analysis and tar composition. In another work, Li et al ${ }^{17}$ used the same rotary kiln to study the characteristics of gases produced by pyrolysis of various municipal solid wastes including wood under different operating conditions. Kabir et al ${ }^{18}$ presented an experimental and numerical approach to study the pyrolysis of municipal green waste. The experimental pyrolysis was performed at a final temperature of $500^{\circ} \mathrm{C}$ in a rotary furnace. Mass balance of the process was established, but gas, tar and char were not characterized.

The purpose of this work is to analyze pyrolysis process at high-temperature (from 700 to $900^{\circ} \mathrm{C}$ ) in order to maximise the pyrolysis gases (volatiles) yield. Experiments were performed with green waste and wood pellets in a pilot-scale rotary kiln with a feedstock mass flow rate of $6 \mathrm{~kg} / \mathrm{h}$. Product yields from both biomass sources were determined. Gas composition, tar qualitative then quantitative analysis, as well as char characterization, were performed. Their variation is thoroughly studied as a function of the reactor temperature. Furthermore, the possible influence of inorganic matter on product yields and composition is discussed. 


\section{Materials and methods}

\subsection{Biomass and characterization methods}

Green waste and a mixture of oak and beech sawdust were selected. Green waste was supplied by the French company AGRI 2000. It consists of garden waste which contains mostly small branches. Its availability and abundance in France were demonstrated recently by Solagro and E\&E Consultant investigations ${ }^{19}$. It was ground and pelletized into uniform cylindrical pellets with a diameter of $6 \mathrm{~mm}$, a length between 6 and $10 \mathrm{~mm}$ and an apparent pellet density of 624 $\mathrm{kg} / \mathrm{m}^{3}$.

Wood pellets (uniform mixture of oak and beech sawdust) which were produced by the French company S.C.A DE DESHYDRATION DE LA HAUTE-SEINE, were considered as biomass of reference. The wood cylindrical pellets have a diameter of $6 \mathrm{~mm}$, a length between 11 and $15 \mathrm{~mm}$ and an apparent density of $688 \mathrm{~kg} / \mathrm{m}^{3}$.

\subsubsection{Ultimate and proximate analysis}

According to the French standard NF V 03-921, the moisture content was determined by weight difference after drying a biomass sample for $2 \mathrm{~h}$ at $105^{\circ} \mathrm{C}$. The French standard NF MO3-004 was used to evaluate volatile matter contents. A biomass sample was ground and placed in a preheated furnace at $900 \pm 5^{\circ} \mathrm{C}$ during $7 \mathrm{~min}$. For ash content evaluation, the French standard NF MO3-004 was used. A ground biomass sample was introduced into an oven heated from room temperature to $550^{\circ} \mathrm{C}$ and then maintained at $550^{\circ} \mathrm{C}$ for $3 \mathrm{~h}$. Char characterization was the same to biomass except for ash content which was determined at $815^{\circ} \mathrm{C}$. The fixed carbon content was deduced by difference.

An elementary analyzer CHNS-O (FLASH 2000) was used for ultimate analysis. Oxygen content was determined by difference. To determine the composition of the inorganic (metals and non-metals), $150 \mathrm{mg}$ of ground and dried biomass were acid digested in closed vessels at 
$220^{\circ} \mathrm{C}$ during $24 \mathrm{~h} . \mathrm{H}_{2} \mathrm{O}_{2}$, acid reagents $\mathrm{HNO}_{3}$ and $\mathrm{HF}$ were used according to the standard $\mathrm{EN}$ 16967. Acid solutions were diluted with demineralized water to $50 \mathrm{ml}$ and analyzed using HORIBA Jobin Yvon Ultuma 2 inductively coupled plasma optical emission spectrometer (ICP-OES).

\subsubsection{Higher heating value (HHV)}

The HHV was obtained with the calorimetric bomb IKA C5000. A mass of $500 \mathrm{mg}$ of dried biomass or char was introduced into the calorimetric bomb to undergo a combustion reaction. The Lower Heating Value (LHV) was determined using the relationship between the HHV and LHV ${ }^{20}$ according to equation 1 :

$$
L H V=H H V-h_{g}(9 H / 100+M / 100)
$$

Where $\mathrm{H}, \mathrm{h}_{\mathrm{g}}$ and $\mathrm{M}$ are hydrogen percentage, water latent heat of vaporization $(2260 \mathrm{~kJ} / \mathrm{kg})$ and moisture percentage respectively.

\subsubsection{Composition analysis}

Biomass extractives, hemicelluloses and lignin content were determined following the protocol of Li et al. ${ }^{21}$ as well as the standards TAPPI T204 om-88 and TAPPI T22 om-88. The cellulose content was determined by difference. Biomass samples were previously ground to obtain a particle size below $500 \mu \mathrm{m}$.

- Extractives quantification

Extractives were obtained from about $3 \mathrm{~g}$ of a dried biomass sample $\left(\mathrm{m}_{0}\right)$ using acetone and a Soxhlet extractor during 6h. Afterwards, the residue was mixed with distilled water placed in a flask above a reflux system. Then, it was brought to boiling during $1 \mathrm{~h}$. Finally the residue was dried in an oven at $105^{\circ} \mathrm{C}$ and weighted to obtain the mass $\left(\mathrm{m}_{1}\right)$. The extractives wt.\% were calculated according to equation 2 : 


$$
E_{x}=\frac{m_{0}-m_{1}}{m_{0}} 100
$$

The same biomass residue obtained from this experiment is used to determine the hemicellulose and lignin contents

- Hemicellulose quantification

A volume of $150 \mathrm{~mL}$ of a $20 \mathrm{~g} / \mathrm{L} \mathrm{NaOH}$ solution was added to approximately $1 \mathrm{~g}\left(\mathrm{~m}_{2}\right)$ of the residue obtained from the extractives analysis. The mixture was boiled for $3.5 \mathrm{~h}$ with a reflux system. The resulting solid was filtered, washed 4 times with $150 \mathrm{~mL}$ of distilled water to remove $\mathrm{Na}^{+}$. Then the residue was put in an oven to dry at $105^{\circ} \mathrm{C}$. Finally, it was weighted to obtain the mass $\left(\mathrm{m}_{3}\right)$. The hemicellulose (wt.\%) was calculated according to equation 3 :

$H_{x}=\frac{m_{3}-m_{2}}{m_{2}}\left(100-E_{x}\right)$

- Lignin quantification

$30 \mathrm{~mL}$ of $72 \%$ sulphuric acid solution was slowly added to approximately $1 \mathrm{~g}\left(\mathrm{~m}_{4}\right)$ of the residue obtained from the extractives analysis. The mixture was maintained at $7^{\circ} \mathrm{C}$ for $2 \mathrm{~h}$. Then a volume of $300 \mathrm{~mL}$ of distilled water was added and the whole boiled during $1 \mathrm{~h}$ with a reflux system. Finally, the residue was filtered, washed 3 times with $150 \mathrm{~mL}$ of distilled water to remove sulphate ions. To obtain the mass $\left(\mathrm{m}_{5}\right)$, the residue was dried at $105^{\circ} \mathrm{C}$ and weighed. The lignin content was determined according to equation 4:

$$
L_{x}=m_{5} / m_{4}\left(100-E_{x}\right)
$$

- Cellulose quantification

The cellulose was deduced by difference according to equation 5:

$$
C_{x}=100-\left(H_{x}+L_{x}+\mathrm{E}_{\mathrm{x}}\right)
$$




\subsection{Pyrolysis process}

Pyrolysis experiments were carried out in the RAPSODEE centre pilot-scale rotary kiln (Figure 1). It consists of a $4.2 \mathrm{~m}$ long cylinder of $0.210 \mathrm{~m}$ internal diameter and a $2.5 \mathrm{~m}$ effective heated length. Its inner wall is covered by a metal grid. Its inclination can vary between $0^{\circ}$ and $7^{\circ}$ and its rotational speed between 1 and $21 \mathrm{rpm}$. In order to work in conditions closed to industrial ones and be able to optimize energy efficiency, we have chosen to maintain solid residence time inferior to $1 \mathrm{~h}^{22}$. It was obtained under ambient temperature conditions by combining different inclinations $\left(1.5-3^{\circ}\right)$ and rotational speeds $(2-3 \mathrm{rpm})$. Presenting the results of all the tested combinations is not relevant for this paper. The couple retained for all the pyrolysis experiments is an inclination of $3^{\circ}$ with a rotation speed of $3 \mathrm{rpm}$, which gives a solid residence time of 38 min in the case of wood pellets and $41 \mathrm{~min}$ for green waste pellets. The tube is divided into five zones and the reactor is heated by its electrical resistances with a power of $38 \mathrm{~kW}$. Three ' $\mathrm{K}$ ' thermocouples were positioned inside the reactor. The maximum working temperature of the reactor was $1000^{\circ} \mathrm{C}$ (with a heating rate of $6^{\circ} \mathrm{C} / \mathrm{min}$ ). The hopper where the biomass is initially introduced has a capacity of $26 \mathrm{~kg}$. The biomass can be transported from there to the cylinder inlet through a vibrating conveyor. The overall feeding system is continuously weighed. The control of the conveyor vibration amplitude allows the regulation of the biomass inlet mass flow rate. At the other end of the cylinder, a metal pot is used to collect the produced char.

\subsection{Pyrolysis protocol}

In all experiments, biomass mass flow rate of approximately $6 \mathrm{~kg} / \mathrm{h}$ was fed into the reactor. It seemed reasonable to assume that steady-state will be reached after a period of time estimated at three folds the solid residence time. Figure $\mathbf{2}$ confirms actually this estimation, so for all the experiments, whatever the temperature 700,800 or $900^{\circ} \mathrm{C}$, biomass feeding into the reactor started $2 \mathrm{~h}$ before the char collection and the gas and bio-oil sampling. The char collection, as well as the gas and bio-oil sampling, lasted for $45 \mathrm{~min}$. At $\mathrm{t}_{\mathrm{o}}$, the hopper weight is noted and 
the char metal pot is replaced with an empty one. Simultaneously the gas analysis and bio-oil sampling are started. Once the $45 \mathrm{~min}$ is over, the gas analysis and bio-oil sampling are stopped along with biomass feeding. The hopper weight is noted and the char metal pot is replaced. Char is kept under nitrogen flow then weighted. For both biomasses, every single experiment was conducted twice to ensure the repeatability. The relative error was less than $5 \%$

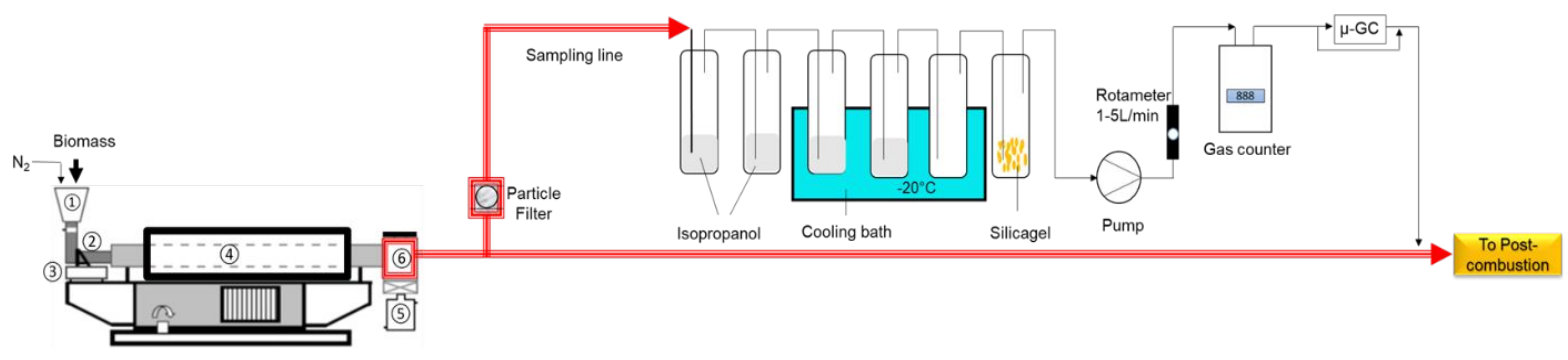

Figure 1: Schematic representation of the rotary kiln pyrolysis reactor connected to the gas and tar sampling and analysis system. 1: feeding hopper, 2: vibrating conveyor, 3: weighing system, 4: rotating cylinder, 5: char recovering tank, 6: smoke box

\subsection{Gas and tar sampling and analysis}

The condensing system consisted of six impinger bottles connected in series. $300-400 \mathrm{~mL}$ of isopropanol was added to each bottle, except for the fifth which was left empty and the last one which was filled with silica gel. The gas and bio-oil sampling were performed at a flow rate of $2 \mathrm{~L} / \mathrm{min}$ using a rotameter. The gas chromatograph (490 Micro GC, Agilent) was used to analyse the non-condensable gases $\left(\mathrm{H}_{2}, \mathrm{CO}, \mathrm{CH}_{4}, \mathrm{CO}_{2}, \ldots\right)$. Gas concentrations were calculated on nitrogen-free basis. The nitrogen gas $(4 \mathrm{NL} / \mathrm{min})$ was used as a tracer for mass balance. To establish the mass balance, the sampled bio-oil flow rate was determined by weighting the condensation system (with isopropanol) before and after the pyrolysis process. The flow rate of the sampled permanent gases was determined by a gas counter meter. The mass flow-rate and yield of permanent gases at the reactor outlet were calculated using data from the micro-GC and the mass conservation equation for the tracer gas $\left(\mathrm{N}_{2}\right)$ as follows in equation 6 and 7 : 
$\dot{m}_{g p}=\frac{\dot{m}_{N 2}}{Y_{N 2}}-\dot{m}_{N 2}$

$\eta_{g p}=\frac{\dot{m}_{g p}}{\dot{m}_{\text {biomass daf }}}$

Where $\mathrm{Y}_{\mathrm{N} 2}$ and $\dot{m}_{N 2}$ are the nitrogen mass fraction in the permanent gases and mass flow rate respectively. $\dot{m}_{\text {biomass daf }}$ is the biomass mass flow rate on dry ash-free basis. $\eta_{g p}$ and $\dot{m}_{g p}$ are the permanent gases yield (wt. \% daf) and mass flow rate respectively.

The bio-oil mass flow rate and its yield were determined by equation 8 :

$\dot{m}_{\text {bio-oil }}=\dot{m}_{g p} \frac{\dot{m}_{\text {bio }- \text { oil. sampled }}}{\dot{m}_{\text {gp. sampled. }}}$

$\dot{m}_{\text {bio-oil }}$ is bio-oil mass flow rate.

The char was collected and weighted to determine its mass flow rate and yield according to equation 9.

$\eta_{\text {char }}=\frac{\dot{m}_{\text {char }}}{\dot{m}_{\text {biomass daf }}}$

$\eta_{\text {char }}$ and $\dot{m}_{\text {char }}$ are the char yield (wt. \% daf) and mass flow rate respectively.

For all experiments, the mass balance was closed to $85-94 \%$. The non-closure can be attributed to the premature cooling of bio-oil within the flow paths. It can also be due to the fact that light hydrocarbons contained in the analyzed gas might go undetected. Furthermore, during the impinger bottles weighing at room temperature, the volatilization of the light compounds contained in the bio-oil might also occur. In this study, the lacking amount in the mass balance was assumed to be essentially due to the premature cooling of bio-oil. Indeed, to prevent any overpressure in the reactor, a rupture disc has been installed at the reactor outlet limiting the electrical tracing of this zone ( 6 on Figure 1$)$ to $200^{\circ} \mathrm{C}$. Hence, the mass balance closure was ensured by adding the lacking mass to the bio-oil. The produced pyrolysis liquid fraction (bio- 
oil), is defined as the sum of organic liquid (tar), water pyrolytic and water in feedstock. In order to compare the results of the two biomasses, the mass balance was calculated on dry ashfree (daf) basis.

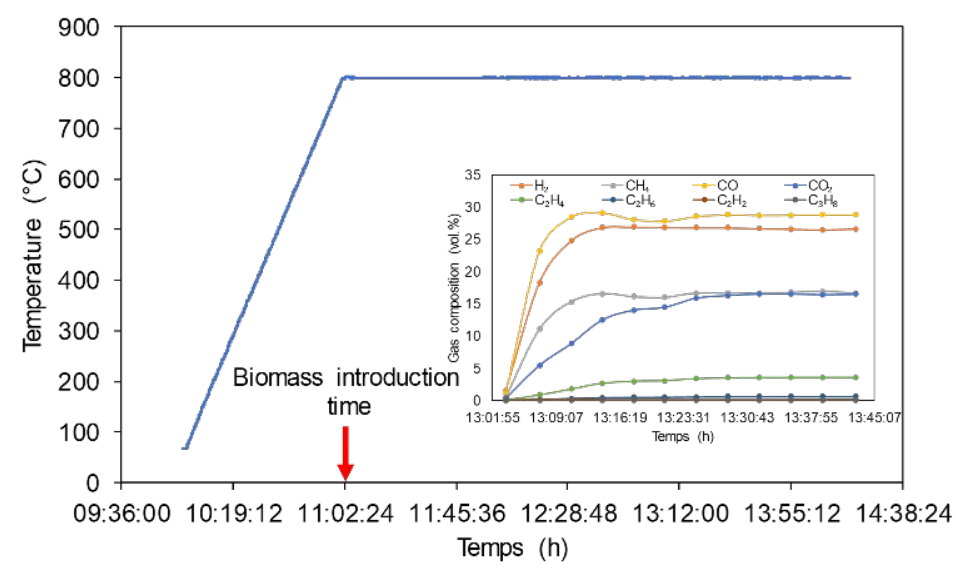

Figure 2: Gas composition variation with time

2.5 Bio-oil analysis

For reminder, what is called bio-oil is a tar and water mixture.

\subsubsection{Water content determination}

Water content in bio-oil was measured by Karl Fisher (METTLER TOLEDO V30) titration using HYDRANAL methanol dry as solvent and HYDRANAL Composite 5 as titrant. Pyrolytic water $\left(\eta_{\text {water }}\right)$ and tar $\left(\eta_{\text {tar }}\right)$ yields were then determined according to equation 10 and 11:

$$
\begin{aligned}
\eta_{\text {Water }}=\frac{\dot{m}_{\text {bio }- \text { oil }} \frac{W K}{100}-\dot{m}_{0} \frac{H_{0}}{100}}{\dot{m}_{\text {biomass daf }}} \\
\eta_{\text {Tar }}=\frac{\dot{m}_{\text {bio - oil }}\left(1-\frac{W K}{100}\right)}{\dot{m}_{\text {biomass daf }}}
\end{aligned}
$$


Where $\dot{\mathrm{m}}_{0}$ and $H_{0}$ are initial mass flowrate of biomass $(\mathrm{kg} / \mathrm{h})$ and humidity in the biomass (wt.\%) respectively. WK is the water content in condensates determined by Karl Fischer analysis (wt.\%).

\subsubsection{Bio-oil analysis by GC/MS}

The analysis of bio-oil was performed using a Shimadzu GCMS-TQ 8030 (Tokyo. Japan) Gas Chromatograph Mass Spectrometer. Chromatographic separation was performed on a Rxi-5Sil MS (30 m x $0.25 \mathrm{~mm}, 0.25 \mu \mathrm{m}$ film thickness, Resteck) column using helium as a carrier gas at a $3.0 \mathrm{~mL} / \mathrm{min}$ constant flow. The column oven temperature evolution was programmed as follows: first, it was set at an initial value of $40^{\circ} \mathrm{C}$ which was held for $5 \mathrm{~min}$. After that $280^{\circ} \mathrm{C}$ was reached (with a $5^{\circ} \mathrm{C} / \mathrm{min}$ rate) and maintained for $2 \mathrm{~min}$. A volume of $1 \mu \mathrm{L}$ was injected at $250^{\circ} \mathrm{C}$ in split mode using 1:10 split ratio. The mass spectrometer was operated in the electron impact (EI) ionization mode (electron energy was $70 \mathrm{eV}$ ). The interface and ion source temperatures were respectively set at $260^{\circ} \mathrm{C}$ and $200^{\circ} \mathrm{C}$. For qualitative analysis, the detection was performed in full scan mode in a $35-600 \mathrm{~m} / \mathrm{z}$ range. It is important to note that the tar composition determination is extremely complex given the high number of species to identify. In this study, compounds with a surface area greater than $2 \%$ and some compounds with a surface area of less than $2 \%$ but very specific to one of the two biomasses, were taken into consideration. For quantitative analysis, the selected ion monitoring (SIM) detection mode was performed with 3 qualifier ions for each component. The amount of each component was determined by an external standard method with 10 standard samples (Benzene, toluene, mcresol, m,p-xylene, styrene, naphthalene, fluorene, biphenyl and phenol). The compounds were quantified using calibration curves, which were produced by an analysis of pure substances by GC/MS. 


\section{Results and discussion}

\subsection{Samples characteristics}

The two biomass samples chemical composition, their proximate and ultimate analysis along with their energy content are listed in Table 1. The moisture contents of the two biomasses were $7.32 \mathrm{wt} \%$ for green waste and 7.75 wt.\% for wood. The biomasses show similar characteristics. However, the ash content of green waste pellets (2.69 wt.\%) was higher than that in wood pellets $(0.88 \mathrm{wt} \%)$. The effects of mineral matter on volatile and char yields obtained during biomass pyrolysis have been extensively studied in literature ${ }^{23,24}$. Raveendran et al ${ }^{23}$ concluded that the mineral matter of biomass, in combination with the organic composition, plays a major role in determining pyrolysis product distribution and product properties. Whereas the organic composition of the two biomasses is similar, their mineral composition presents actually some differences. Indeed, Green waste has more alkali (K), alkaline earth $(\mathrm{Ca}, \mathrm{Mg})$ metals and silicon than wood. 
Table 1: Analyses of pellets sample

Green waste pellets

Wood pellets

\begin{tabular}{lcc}
\hline Proximate analysis (wt.\% dry basis) & \\
\hline Volatile matter & 79.31 & 82.48 \\
Ash & 2.69 & 0.88 \\
Fixed carbon & 18.00 & 16.64 \\
\hline Ultimate analysis (wt.\% dry ash-free) & & \\
\hline $\mathrm{C}$ & 50.20 & 49.76 \\
$\mathrm{H}$ & 5.76 & 5.96 \\
$\mathrm{~N}$ & 0.36 & 0.14 \\
$\mathrm{O}$ & & 44.14 \\
$\mathrm{H} / \mathrm{C}^{2}$ & 43.68 & 1.44 \\
$\mathrm{O} / \mathrm{C}^{2}$ & 1.38 & 0.67 \\
\hline
\end{tabular}

Chemical Analysis (wt.\% dry basis)

\begin{tabular}{lcc}
\hline Extractives & 8.81 & 9.99 \\
Lignin & 27.78 & 26.08 \\
Hemicelluloses & 24.04 & 26.29 \\
Cellulose & 39.36 & 37.64 \\
\hline Inorganic elements (mg/kg of biomass dry basis) & & 89.07 \\
\hline Iron (Fe) & 391.77 & 838.53 \\
Calcium (Ca) & 2070 & 94.40 \\
Potassium(K) & 163.72 & 45.88 \\
Magnesium(Mg) & 220.24 & 127.86 \\
Silicon (Si) & 1218.41 & \\
\hline Energy content & & 19.51 \\
\hline HHV (MJ/kg) & 19.25 & 19.68 \\
HHV(MJ/kg daf) & 19.78 & \\
\hline
\end{tabular}

\footnotetext{
${ }^{1}$ by difference

2 molar ratio
} 


\subsection{Effect of temperature on products yield}

Figure 3 displays the two biomasses product yields as a function of temperature $\left(700-900^{\circ} \mathrm{C}\right)$. As expected, the temperature increase results in gas yield increase along with tar, water and char reduction. Those results are in agreement with the well known fact of gas production enhancement by high temperatures. Indeed, it is reported in the literature that the secondary reactions such as thermal cracking, repolymerization and recondensation are favored by the temperature increase $\mathrm{e}^{11,25}$. Whereas the gas yield from green waste increases from 45 to $61 \mathrm{wt}$. $\%$ daf, the one produced by wood increases from 45 to $59 \mathrm{wt} . \%$ daf. The increase of green waste gas yield between $800-900^{\circ} \mathrm{C}$ is clearly more significant than that of wood. Since the two biomasses have similar organic composition, the discrepancy observed in gas yield can be attributed to ash amount and composition. As mentioned previously, green waste contains more ash. Juchelkovà et $\mathrm{al}^{26}$ reported that ash content can be associated with the increase in pyrolysis gas production. The alkali $(\mathrm{K})$ and alkaline earth metals such as $\mathrm{Ca}$ and $\mathrm{Mg}$ may catalyse the thermal degradation of biomass.

The evolution with temperature of water and tar yields produced from each biomass is represented in Figure 3. Less tar $\left(12\right.$ wt. $\%$ daf at $\left.700^{\circ} \mathrm{C}\right)$ and more water are produced with wood. In addition, the tar yield, 8 wt. $\%$ daf, remains constant between $800^{\circ} \mathrm{C}$ and $900^{\circ} \mathrm{C}$. Tar amount produced from green waste decreases slowly from 15.8 to $12.9 \mathrm{wt} . \%$ daf between $700^{\circ} \mathrm{C}$ and $800^{\circ} \mathrm{C}$ to reach $9.2 \mathrm{wt} . \%$ at $900^{\circ} \mathrm{C}$. Globally, between 700 and $900^{\circ} \mathrm{C}$, tar yields from green waste and wood decreases by $42 \%$ and $33 \%$ respectively. Compared to wood, the significant reduction of tar yield in the case of green waste may also be caused by mineral content ${ }^{27}$. The decrease of tar and water with the increase of temperature might be due to steam reforming reactions which favour gas production. According to Di Blasi ${ }^{6}$, water is a product of the reactions of tar degradation and so its yield increases with temperature. It could be a means to 
evaluate the extent of cracking reactions. However, water consumption depends on the steam reforming reaction rate which can be influenced by the presence of inorganic matter ${ }^{28}$.

The char produced from green waste decreases from 22.4 to $16.9 \mathrm{wt} . \%$ daf and the one produced from wood from 20.4 to 17.4 wt.\% daf with wood. These reductions can be explained by competition between the secondary reactions of char and volatile formation which leads to more production of light non-condensing gas causing the increase of gas yield ${ }^{6,29}$.
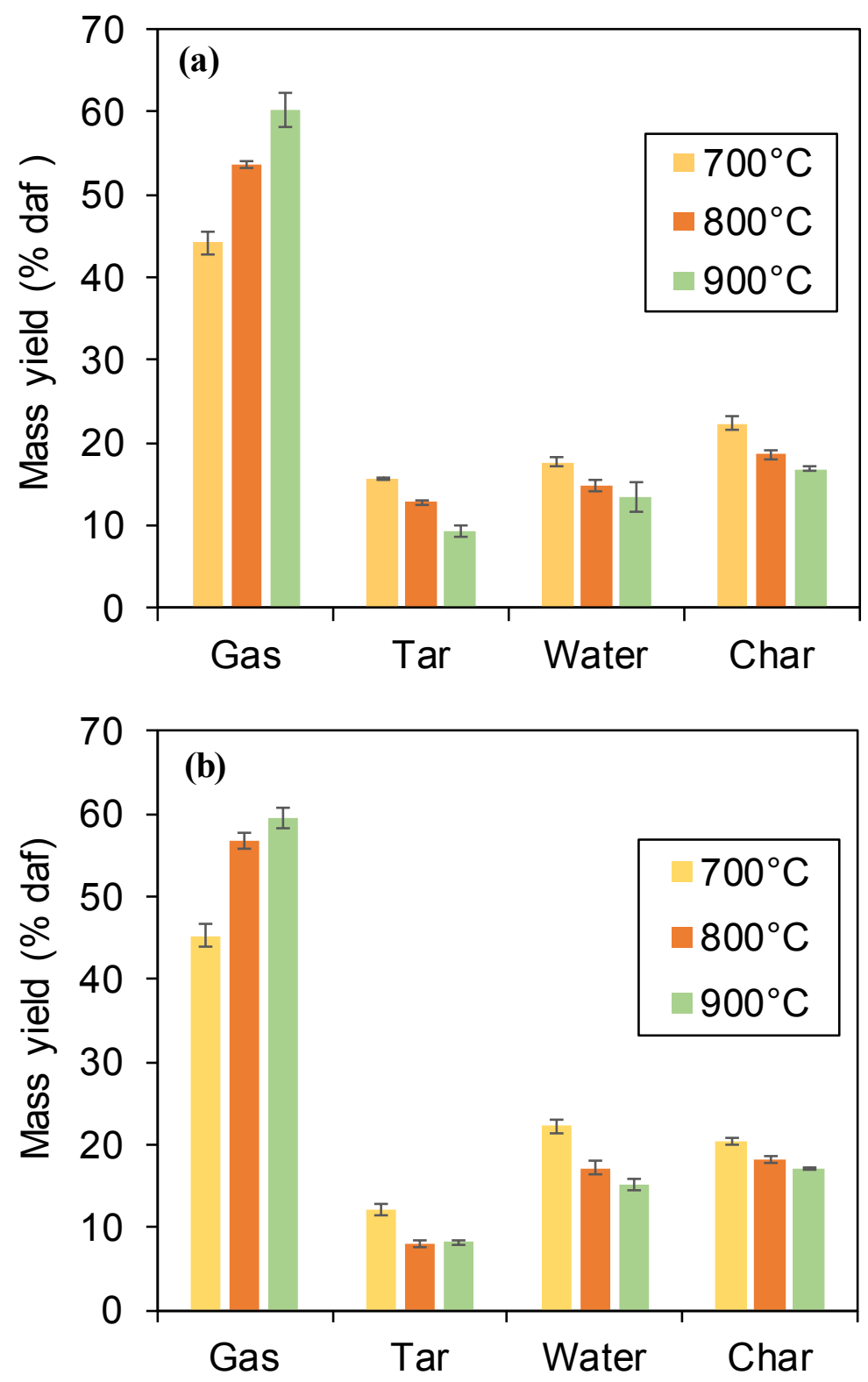

Figure 3: Green waste (a) and Wood (b) pyrolysis products mass balances 
3.3 Influence of temperature on gas composition

Figure 4 shows the gas composition $\left(\mathrm{N}_{2}\right.$ free) under the three considered temperatures. For both biomasses, carbon monoxide $(\mathrm{CO})$ is the main gas at 700 and $800^{\circ} \mathrm{C}$. $\mathrm{CO}$ amount from wood pyrolysis remains almost constant from $800^{\circ} \mathrm{C}$ to $900^{\circ} \mathrm{C}$. The same behavior was observed by Gao et $\mathrm{al}^{13}$ between 600 and $900^{\circ} \mathrm{C}$. On the other hand, carbon monoxide increases during green waste pyrolysis from $27.8 \%\left(800^{\circ} \mathrm{C}\right)$ to $34.5 \%\left(900^{\circ} \mathrm{C}\right)$. This can be explained by the enhancement of the decarbonylation reaction. Hydrogen $\left(\mathrm{H}_{2}\right)$ content increases with temperature for both biomasses. For green waste, $\mathrm{H}_{2}$ content increases from $23.5 \%$ at $700^{\circ} \mathrm{C}$ to $36.7 \%$ at $900^{\circ} \mathrm{C}$. Similarly, it increases for wood, from $18.9 \%$ at $700^{\circ} \mathrm{C}$ to $35.93 \%$ at $900^{\circ} \mathrm{C}$. This is due to the thermal cracking reactions which are favoured with temperature. According to Zhang et $\mathrm{al}^{30}$, secondary reactions of tar and char via cracking, steam reforming and char gasification are responsible for $\mathrm{H}_{2}$ and $\mathrm{CO}$ production. $\mathrm{CH}_{4}$ and $\mathrm{CO}_{2}$ concentrations decrease with increasing temperature for both biomasses. Fagbemi et al ${ }^{11}$ observed similar tendencies when they performed wood pyrolysis between 400 and $900^{\circ} \mathrm{C}$. They found that in the 700 $900^{\circ} \mathrm{C}$ range, the $\mathrm{CO}_{2}$ concentration decreased from 16.7 to $5.0 \%$. Similarly, the $\mathrm{CH}_{4}$ concentration decreased from 16 to $12 \%$. In addition, it presented a maximum value around $750^{\circ} \mathrm{C}$. De Conto and al. ${ }^{14}$ reported that elephant grass pyrolysis presents a maximum releasing rate of $\mathrm{CH}_{4}$ and $\mathrm{CO}_{2}$ at approximately $500^{\circ} \mathrm{C} . \mathrm{CO}_{2}$ decreasing could be attributed to the fact that the majority of it is produced by decarboxylation at low temperatures and dry reforming reactions at high temperatures. These two reactions could lead to the reduction of $\mathrm{CO}_{2}$ concentration. $\mathrm{CH}_{4}$ content reduction may be due to reforming reactions. The effect of temperature on $\mathrm{C}_{2}-\mathrm{C}_{3}$ concentrations is insignificant from 700 to $800^{\circ} \mathrm{C}$ but their concentrations decrease significantly at $900^{\circ} \mathrm{C}$. It was reported that high temperature favors the production of $\mathrm{H}_{2}$ to the detriment of light hydrocarbons (in $\mathrm{C}_{2}, \mathrm{C}_{3}$ ) which are dehydrogenated by thermal cracking $^{11}$. The composition of pyrolysis gas is clearly affected by the reactor temperature. At 
high temperatures, the pyrolysis gases undergo secondary reactions such as tar cracking and homogeneous reactions. This leads to a much higher production of $\mathrm{H}_{2}$ and $\mathrm{CO}$ concentrations. Many reactions have been identified and published in the literature. Depending on the process conditions (pressure, temperature...) some reactions can prevail in comparison to others. For increasing $\mathrm{H}_{2}$ production at atmospheric pressure and a temperature between $700{ }^{\circ} \mathrm{C}$ and 900 ${ }^{\circ} \mathrm{C}$, Yang and al. ${ }^{31}$ pointed out that the following reactions (R1 to R4) might be favored or not depending on the type of secondary reactions.

$$
\begin{gathered}
\mathrm{CO}+\mathrm{H}_{2} \mathrm{O} \rightarrow \mathrm{H}_{2}+\mathrm{CO}_{2} \\
\mathrm{C}+\mathrm{H}_{2} \mathrm{O} \rightarrow \mathrm{CO}+\mathrm{H}_{2} \\
\mathrm{C}_{\mathrm{m}} \mathrm{H}_{\mathrm{n}}+\mathrm{nH}_{2} \mathrm{O} \rightarrow \mathrm{nCO}+\left[\mathrm{n}+\left(\frac{\mathrm{m}}{2}\right)\right] \mathrm{H}_{2} \\
\mathrm{C}_{\mathrm{m}} \mathrm{H}_{\mathrm{n}}+2 \mathrm{nH}_{2} \mathrm{O} \rightarrow \mathrm{nCO}_{2}+\left[2 \mathrm{n}+\left(\frac{\mathrm{m}}{2}\right)\right] \mathrm{H}_{2}
\end{gathered}
$$

The increase of $\mathrm{H}_{2}$ production can be an indicator of the secondary reactions significant occurrence ${ }^{31,32}$. In this contribution, when comparing the mass balance of both biomasses, no significant difference is observed. However, the gas composition produced during the pyrolysis of green waste pellets suggests that cracking and homogeneous reactions are more intense. This can be explained by the amount of alkaline earth metals in the green waste (Table 1). Indeed, according to the literature, potassium $(\mathrm{K})$ has the greatest influence on the thermal conversion properties of biomass especially with its catalytic effect on secondary cracking reactions ${ }^{33-35}$. The green waste pellets had more calcium $(\mathrm{Ca})$, Potassium $(\mathrm{K})$ and Iron $(\mathrm{Fe})$ which can favourably influence the secondary reactions.

The $\mathrm{H}_{2} / \mathrm{CO}$ ratio increases with the increase of temperature for the two biomasses to reach 1 at $900^{\circ} \mathrm{C}$, but it remains much lower than the required ratio for syngas applications, i.e methanation or Fischer-Tropsch synthesis. Table 2 shows that $\mathrm{CO}+\mathrm{H}_{2}$ (syngas) total 
concentration reaches $70 \%$ at $900^{\circ} \mathrm{C}$ for both biomasses. The lower heating value of the produced gas has been calculated using the following equation ${ }^{31}$.

$$
\mathrm{LHV}=4.2\left(30 \mathrm{CO}+25.7 \mathrm{H}_{2}+85.4 \mathrm{CH}_{4}+151.3 \mathrm{C}_{\mathrm{n}} \mathrm{H}_{\mathrm{n}}\right)
$$

Where $\mathrm{CO}, \mathrm{H}_{2}, \mathrm{CH}_{4}$ and $\mathrm{C}_{\mathrm{n}} \mathrm{H}_{\mathrm{m}}$ are the concentrations (vol.\%) of the $\mathrm{CO}, \mathrm{H}_{2}, \mathrm{CH}_{4}$ and hydrocarbons $\left(\mathrm{C}_{2} \mathrm{H}_{4}\right.$ and $\left.\mathrm{C}_{2} \mathrm{H}_{6}\right)$ respectively. Amongst the $\mathrm{C}_{2}-\mathrm{C}_{3}$ hydrocarbons, $\mathrm{C}_{2} \mathrm{H}_{4}$ and $\mathrm{C}_{2} \mathrm{H}_{6}$ have the highest concentrations. The calculated values are also shown in Table 2. The total gas products heating value decreased from 16 to $14 \mathrm{MJ} / \mathrm{Nm}^{3}$. This corresponds to an intermediate level of heat values for gas fuels that can be directly used for gas engines, gas turbines, chemical formation of methanol and methane.

Table 2: Produced dried gas characteristics

\begin{tabular}{cccc|ccc}
\hline & \multicolumn{3}{c|}{ Green waste pellets } & \multicolumn{3}{c}{ Wood pellets } \\
\hline $\mathrm{T}\left({ }^{\circ} \mathrm{C}\right)$ & 700 & 800 & 900 & 700 & 800 & 900 \\
\hline $\begin{array}{c}\text { Gas mean residence } \\
\text { time (s) }\end{array}$ & 38.42 & 35.20 & 30.37 & 37.54 & 32.42 & 31.17 \\
$\begin{array}{c}\text { Gas volume } \\
(\mathrm{Nm} / \mathrm{kg} \mathrm{daf})\end{array}$ & 0.44 & 0.57 & 0.72 & 0.42 & 0.57 & 0.68 \\
$\mathrm{H}_{2} / \mathrm{CO}(\mathrm{mol} / \mathrm{mol})$ & 0.84 & 0.93 & 1.06 & 0.50 & 0.70 & 1.01 \\
$\mathrm{H}_{2}+\mathrm{CO}(\mathrm{mol} \%)$ & 51.48 & 59.73 & 70.34 & 55.94 & 59.89 & 69.89 \\
$\mathrm{LHV}\left(\mathrm{MJ} / \mathrm{Nm}^{3}\right)$ & 16.75 & 16.38 & 14.08 & 16.85 & 16.74 & 14.39 \\
\hline
\end{tabular}

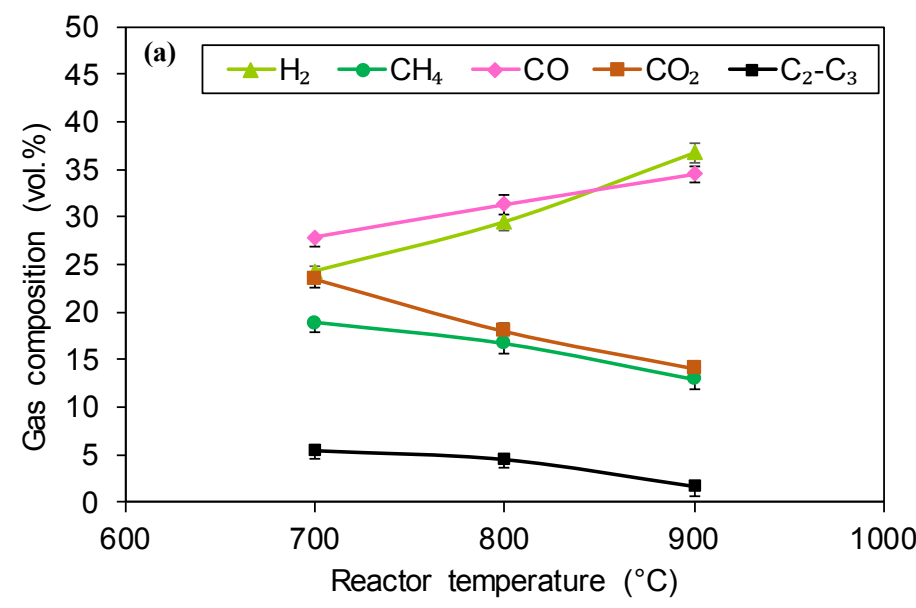




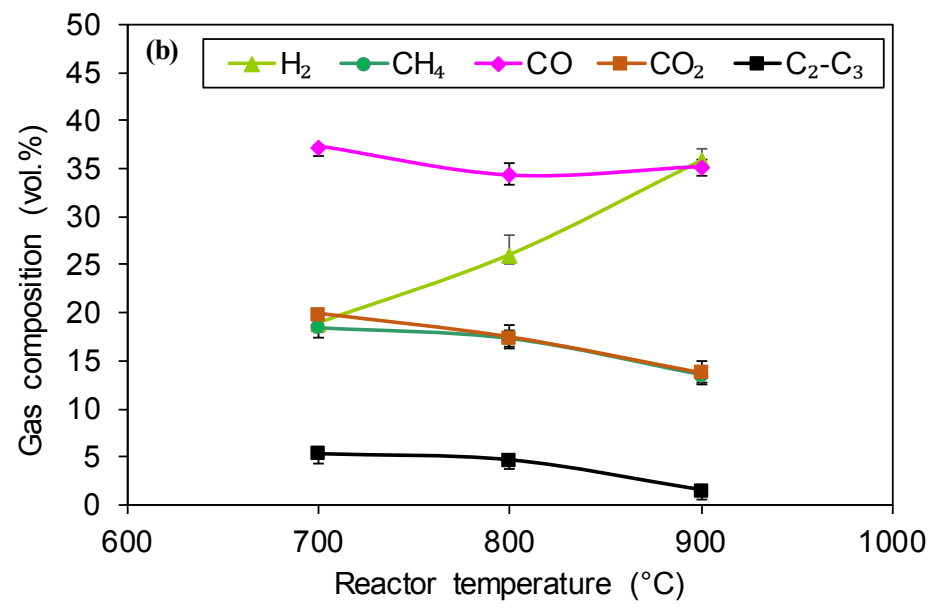

Figure 4: Composition of pyrolysis gas produced from green waste (a) and wood (b)

\subsection{Char characteristics}

Char ultimate and proximate analysis, can be used to extend the understanding of the actual pyrolysis process.

Table 3 reports the results of proximate and ultimate analysis as well as the energy content of the produced char in the present study. The temperature clearly affects char composition. While fixed carbon and ash content increase with temperature, the volatile content decreases. This is consistent with the results reported by Li et al ${ }^{16}$. Green waste has the highest ash content, the fixed carbon content of its char is lower than wood char. On the other hand, both of them are rich in carbon, whose content increases with temperature and is higher in the case of wood. Furthermore, the oxygen content of wood char is lower than green waste char.

It is reported that inorganic matter can form more stable oxides and minerals on the surface of char, which can block their degradation ${ }^{6,27}$. In addition, Song et $\mathrm{al}^{36}$ showed that during the interaction of the pyrolysis tar and char, some O-containing species originating from tar are transferred to the char and form additional O-containing structures in the char matrix. Both approaches can explain (i) the incomplete degradation of green waste (high volatile content) and (ii) the high oxygen amount in green waste char. 
High carbon and low oxygen contents are responsible for the high heating values of the resulting chars. The HHV of green waste char is slightly lower than that of wood char because of the high oxygen content of green waste char. The HHV remains globally between 28 and $34 \mathrm{MJ} / \mathrm{kJ}$. The produced char in the present study is a good fuel due to its high heating value, which is even higher than that of conventional coals $(15-27 \mathrm{MJ} / \mathrm{kg})$.

Table 3: Char characterization

\begin{tabular}{cccc|ccc}
\hline & \multicolumn{3}{c}{ Green waste pellets char } & \multicolumn{3}{c}{ wood pellets char } \\
\hline $\mathrm{T}\left({ }^{\circ} \mathrm{C}\right)$ & 700 & 800 & 900 & 700 & 800 & 900 \\
\hline \multicolumn{7}{c}{ Proximate analysis (wt. \% db) } \\
\hline Volatile matter & 10.16 & 9.03 & 5.07 & 5.02 & 3.37 & 2.09 \\
Ash & 11.45 & 12.36 & 12.82 & 2.69 & 3.02 & 3.21 \\
Fixed carbon & 78.38 & 78.61 & 82.11 & 92.29 & 93.61 & 94.70 \\
\hline \multicolumn{7}{c}{ Ultimate analysis (wt. \% daf) } \\
\hline $\mathrm{C}$ & 87.30 & 89.34 & 92.65 & 94.84 & 96.08 \\
$\mathrm{H}$ & 1.63 & 1.04 & 0.84 & 1.82 & 1.07 & 0.76 \\
$\mathrm{~N}$ & 0.49 & 0.36 & 0.38 & 0.29 & 0.18 & 0.20 \\
$\mathrm{O} *$ & 12.37 & 11.30 & 9.44 & 5.24 & 3.91 & 2.96 \\
\hline \multicolumn{7}{c}{ Higher Heating Value } \\
\hline HHV (MJ/kg) & 29.27 & 28.17 & 27.81 & 33.58 & 32.86 & 32.53 \\
HHV (MJ/kJ daf) & 33.06 & 32.14 & 32.09 & 34.50 & 33.88 & 33.61 \\
\hline
\end{tabular}

\subsection{Tar analysis}

The GC/MS analysis was used to determine the composition of the tar produced from the biomass sources. The qualitative analysis was performed prior to quantitative one.

It is worth mentioning that pyrolysis tar composition is the key factor that will determine the operating conditions for cracking and reforming of pyrolysis vapors. Therefore, The tar compounds produced from the two biomasses at the three considered temperatures $(700,800$, $900^{\circ} \mathrm{C}$ ) are presented in Figure 5 and Table 4 for wood, and Figure 6 and Table 5 for green waste. Whereas the chromatographic peak and the retention time are shown in Figure $\mathbf{5}$ and 
Figure 6, the detailed component analysis, including peak number, compound name and peak area are gathered in Table $\mathbf{4}$ and Table 5.

For a clear and meaningful discussion of the presented results, The compounds have been grouped into the following categories: (i) light aromatics with a single-ring, such as benzene, toluene; (ii) heterocycles, composed of aromatic rings containing heteroatoms such as phenol; (iii) light polyaromatic hydrocarbons (PAHs) with 2 or 3 aromatics rings, such naphthalene, biphenyl, and; (iv) heavy PAHs with more than 3 rings such pyrene, fluorene.

Although the GC/MS analysis does not permit to identify all the compounds, some clear tendencies can be established between tar from wood and tar from green waste. It can be seen that tar from green waste contains $\mathrm{N}$-containing compounds such as pyrrole, pyridine, quinoline, 5-Methylbenzimidazole and indole. This can be related to the high nitrogen content in the green waste biomass. The peak area of light and heavy PAHs increase from 21.6 to 37.6 $\%$ and 3.94 to $16.6 \%$ respectively in the case of the tar produced from green waste. An opposite tendency is observed in the case of the tar produced from wood.

According to the literature, temperature and residence time increase PAHs formation [44]. However, the two biomasses were pyrolyzed in similar conditions. Therefore ash content which is the principal difference between green waste and wood composition might be the reason behind such results. González et al. ${ }^{38}$ pointed out that feedstock characteristics highly influence PAHs concentrations. Solar et al ${ }^{28}$ observed that liquid obtained with biomass impregnated with $44 \mathrm{Ni}$ at $900^{\circ} \mathrm{C}$ contained more fluorene, anthracene and biphenylene.

The peak area of light aromatics with a single-ring, decreases within green waste tar from 60.2 to $45.2 \%$, while it increases within wood tar from 52.1 to $71.95 \%$. The peak area of heterocycles decreases and disappears when the temperature increases. 
According to the GC/MS qualitative analysis, one can conclude that light aromatics with a single-ring and light polyaromatic hydrocarbons (PAHs) with 2 or 3 aromatics rings are the most important compounds, among those that could be identified, within tars produced from biomasses. In addition, more heavy PAHs with more than 3 rings are observed within green waste tars (from 3.94 from 16.62\%).

It is important to remember that the GC/MS quantitative analysis was carried out in order to identify the major tar compounds yield.

Figure 7 presents the yield of each compound identified by a quantitive method. It is important to mention that tar storage conditions and duration impact the concentrations. In this study, the tars were stored in a refrigerator at $4^{\circ} \mathrm{C}$. The complexity of the analysis (calibration and the search for the appropriate diluting factor) extended their storage at least one month. The total tar mass quantified by GC-MS is not equal to the sampled tar total mass. The green waste pellets total tar mass quantified by GC-MS represents $23.68,37.38,48.27 \mathrm{wt} . \%$ of the sampled tars at $700,800,900^{\circ} \mathrm{C}$ respectively. For wood pellets, tar total mass quantified by GC/MS represents $26.62,70.44$ and $69.58 \mathrm{wt} . \%$ of the sampled tars at $700,800,900^{\circ} \mathrm{C}$ respectively. The tar total mass recovery by $\mathrm{GC} / \mathrm{MS}$ becomes better for temperatures above $700^{\circ} \mathrm{C}$. To our knowledge tar quantification in similar conditions to ours has not been reported in the literature to compare our results with.

Benzene and naphthalene yields increase strongly with temperature increase to exceed $80 \mathrm{wt} . \%$ of the quantified compounds. Our analysis revealed that while phenolics (phenol, m-cresol), Toluene, styrene, m,o-xylene disappear at $900^{\circ} \mathrm{C}$, fluorene and biphenyl appear at the same temperature. These results are in agreement with the literature which states that while small molecules (m,o-cresol, m,p-xylene, acetylene...) content decreased gradually with temperature, heavy molecules become gradually predominante ${ }^{39,40}$. For instance, Morf et al ${ }^{41}$ identified phenol as a unique precursor for the formation of naphthalene. The conversion rates could be 
high due to a longer gas residence time in the present work ( $>30 \mathrm{~s}$ in Table 2). Benzene and naphthalene yields increase between 700 and 800 but decreased at $900^{\circ} \mathrm{C}$. This tendency was also observed by Dufour et $\mathrm{al}^{40}$ at $1000^{\circ} \mathrm{C}$ for benzene and from $900^{\circ} \mathrm{C}$ to $1000^{\circ} \mathrm{C}$ for naphthalene. Tar formation and conversion during the pyrolysis or gasification which is a complex process, has been extensively studied ${ }^{31,34}$. Most of the studies on the formation and conversion of tar were carried out on very short residence times, usually less than 10 seconds. In this study, the gases residence times are more than $30 \mathrm{~s}$ (Table 2) that could be responsible of naphthalene and benzene cracking. This could lead to reactions where benzene can lose the $\mathrm{H}^{+}$radical to form phenyl $\left(\mathrm{C}_{6} \mathrm{H}_{5}\right)$. Two phenyls ring can lead to biphenyl and heavy molecules formation through the HACA mechanism from bipheny ${ }^{42}$. Similarly, according to literature, naphthalene can be converted to gas and soot ${ }^{43}$. Both mechanisms could explain the conversion of naphthalene and benzene at $900^{\circ} \mathrm{C}$ at higher residence times compared to the commonly used in literature. 

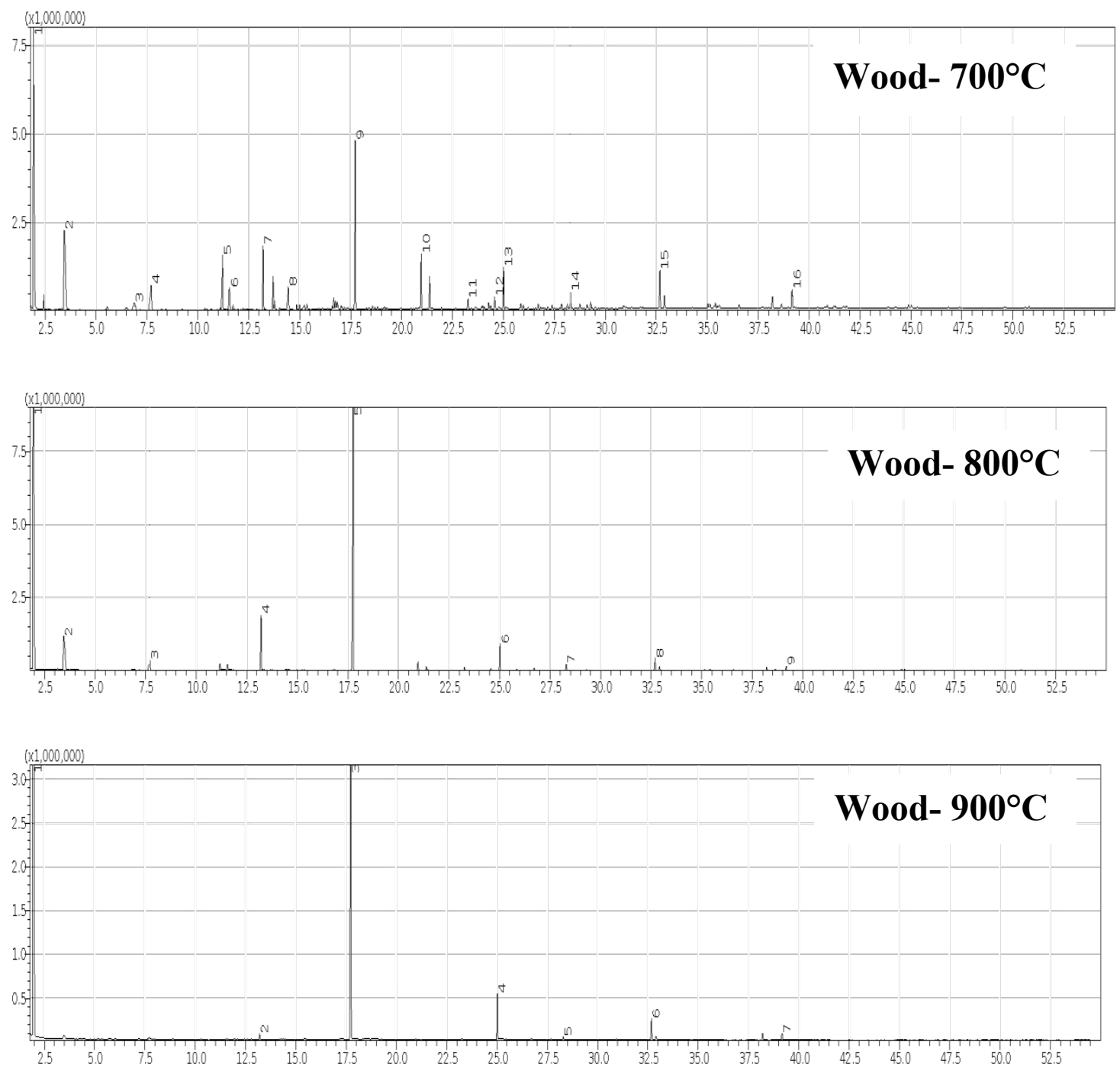

Retention time (min)

Figure 5: GC/MS Chromatogram of wood pyrolysis tar obtained at $700,800,900^{\circ} \mathrm{C}$ 
Table 4: Main wood tar components at different temperatures

\begin{tabular}{|c|c|c|c|c|c|c|}
\hline \multicolumn{3}{|c|}{ Peak number } & \multirow[t]{2}{*}{ Compound } & \multicolumn{3}{|c|}{ Wood / area $(\%)$} \\
\hline 700 & 800 & 900 & & 700 & 800 & 900 \\
\hline 1 & 1 & 1 & Benzene & 30.95 & 58.06 & 71.95 \\
\hline 2 & 2 & & Toluene & 14.87 & 6.83 & \\
\hline 3 & & & o-Xylene & 1.86 & & \\
\hline 4 & 3 & & Styrene or $1,3,5,7$-Cyclooctatetraene & 4.46 & 1.65 & \\
\hline 5 & & & Phenol & 5.69 & & \\
\hline 6 & & & 3-Hydroxyphenylacetylene & 2.75 & & \\
\hline 7 & 4 & 2 & Indene & 5.00 & 4.05 & 0.26 \\
\hline 8 & & & Phenol, 2-methyl- & 3 & & \\
\hline 9 & 5 & 3 & Naphthalene & 14.57 & 25.26 & 24.17 \\
\hline 10 & & & Naphthalene, 2-methyl- & 4.39 & & \\
\hline 11 & & & Biphenyl & 0.84 & & \\
\hline 12 & & & Acenaphthene & 1.13 & & \\
\hline 13 & 6 & 4 & Biphenylene & 3.54 & 2.11 & 2.13 \\
\hline 14 & 7 & 5 & Fluorene & 1.62 & 0.56 & 0.14 \\
\hline 15 & 8 & & Phenanthrene & 3.50 & 1.09 & \\
\hline \multirow[t]{2}{*}{16} & 9 & 7 & Fluoranthene & 1.83 & 0.39 & 0.35 \\
\hline & & 6 & Anthracene & & & 1 \\
\hline
\end{tabular}



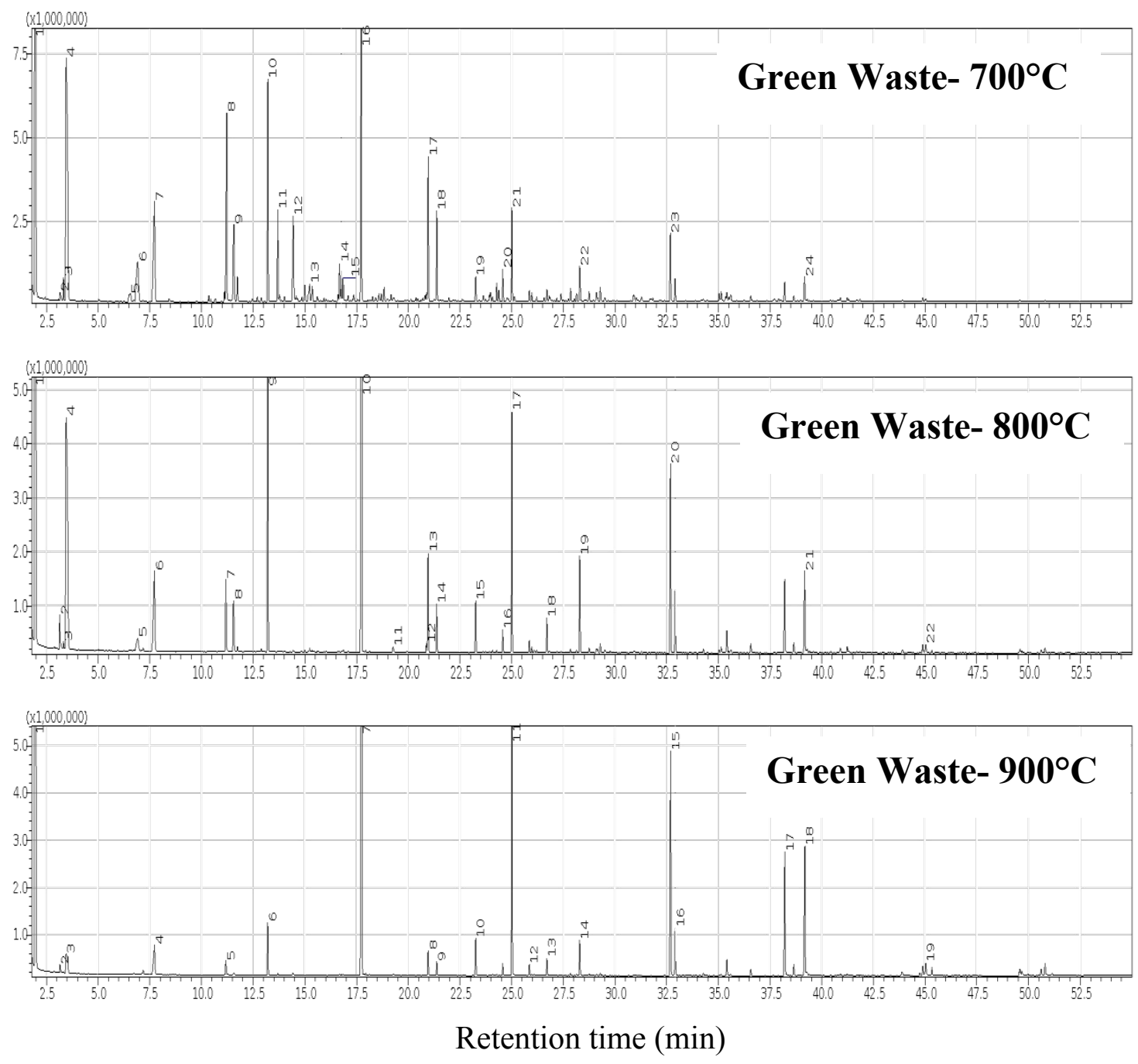

Figure 6: GC/MS Chromatogram of green waste pyrolysis tar obtained at $700,800,900^{\circ} \mathrm{C}$ 
Table 5: Main Green Waste tar components at different temperatures

\begin{tabular}{|c|c|c|c|c|c|c|}
\hline \multicolumn{3}{|c|}{ Peak number } & \multirow[t]{2}{*}{ Compound } & \multicolumn{3}{|c|}{ Green Waste/area (\%) } \\
\hline 700 & 800 & 900 & & 700 & 800 & 900 \\
\hline 1 & 1 & 1 & Benzene & 21.7 & 34.49 & 41.14 \\
\hline 2 & 2 & 2 & Pyridine & 0.31 & 0.64 & 0.19 \\
\hline 3 & 3 & & Pyrrole & 0.42 & 0.13 & \\
\hline 4 & 4 & 3 & Toluene & 16.97 & 11.61 & 1.27 \\
\hline 5 & & & Ethylbenzene & 0.7 & & \\
\hline 6 & 5 & & p-Xylene or o-Xylene & 3.39 & 0.75 & \\
\hline 7 & 6 & 4 & 1,3,5,7-Cyclooctatetraene & 6.02 & 3.10 & 1.5 \\
\hline \multirow[t]{2}{*}{8} & 7 & 5 & Phenol & 6.65 & 1.35 & 0.35 \\
\hline & 8 & & Benzofuran & & 1.21 & \\
\hline 9 & & & Benzene, 1-ethenyl-4-methyl- & 3.45 & & \\
\hline 10 & 9 & 6 & Benzene, 1-propynyl- & 6.04 & 6.23 & 1.29 \\
\hline 11 & & & Phenol, 2-methyl- & 2.29 & & \\
\hline 12 & & & Phenol, 3-methyl- & 3.62 & & \\
\hline 13 & & & 5-Methylbenzimidazole & 0.88 & & \\
\hline 14 & & & $\begin{array}{l}\text { Benzene, (1-methyl-2-cyclopropen- } \\
1 \text {-yl)- }\end{array}$ & 1.22 & & \\
\hline 15 & & & $\begin{array}{l}\text { Cycloprop[a]indene, 1, 1a,6,6a- } \\
\text { tetrahydro- }\end{array}$ & 0.76 & & \\
\hline \multirow[t]{3}{*}{16} & 10 & 7 & Naphthalene & 10.83 & 22.01 & 27.94 \\
\hline & 11 & & Quinoline & & 0.13 & \\
\hline & 12 & & Indole & & 0.16 & \\
\hline 17 & 13 & 8 & Naphthalene, 2-methyl- & 4.05 & 1.99 & 0.61 \\
\hline 18 & 14 & 9 & Naphthalene, 1-methyl- & 2.47 & 0.95 & 0.37 \\
\hline \multirow[t]{4}{*}{19} & 15 & 10 & Biphenyl & 0.69 & 1 & 0.92 \\
\hline & 16 & 12 & Acenaphthene & & 0.45 & 0.28 \\
\hline & 17 & 11 & Acenaphthylene & & 4.95 & 7.06 \\
\hline & 18 & 13 & Dibenzofuran & & 0.68 & 0.46 \\
\hline 20 & & & Naphthalene, 2-ethenyl- & 0.93 & & \\
\hline 21 & & & Acenaphthylene & 2.67 & & \\
\hline 22 & 19 & 14 & Fluorene & 1.1 & 2.08 & 0.97 \\
\hline \multirow[t]{2}{*}{23} & 20 & 15 & Phenanthrene & 2.08 & 4.05 & 6.43 \\
\hline & & 16 & Anthracene & & & 1.35 \\
\hline \multirow[t]{3}{*}{24} & 21 & 17 & Fluoranthene & 0.76 & 1.80 & 3.55 \\
\hline & & 18 & Pyrene & & & 3.83 \\
\hline & 22 & 19 & Triphenylene & & 0.25 & 0.46 \\
\hline
\end{tabular}



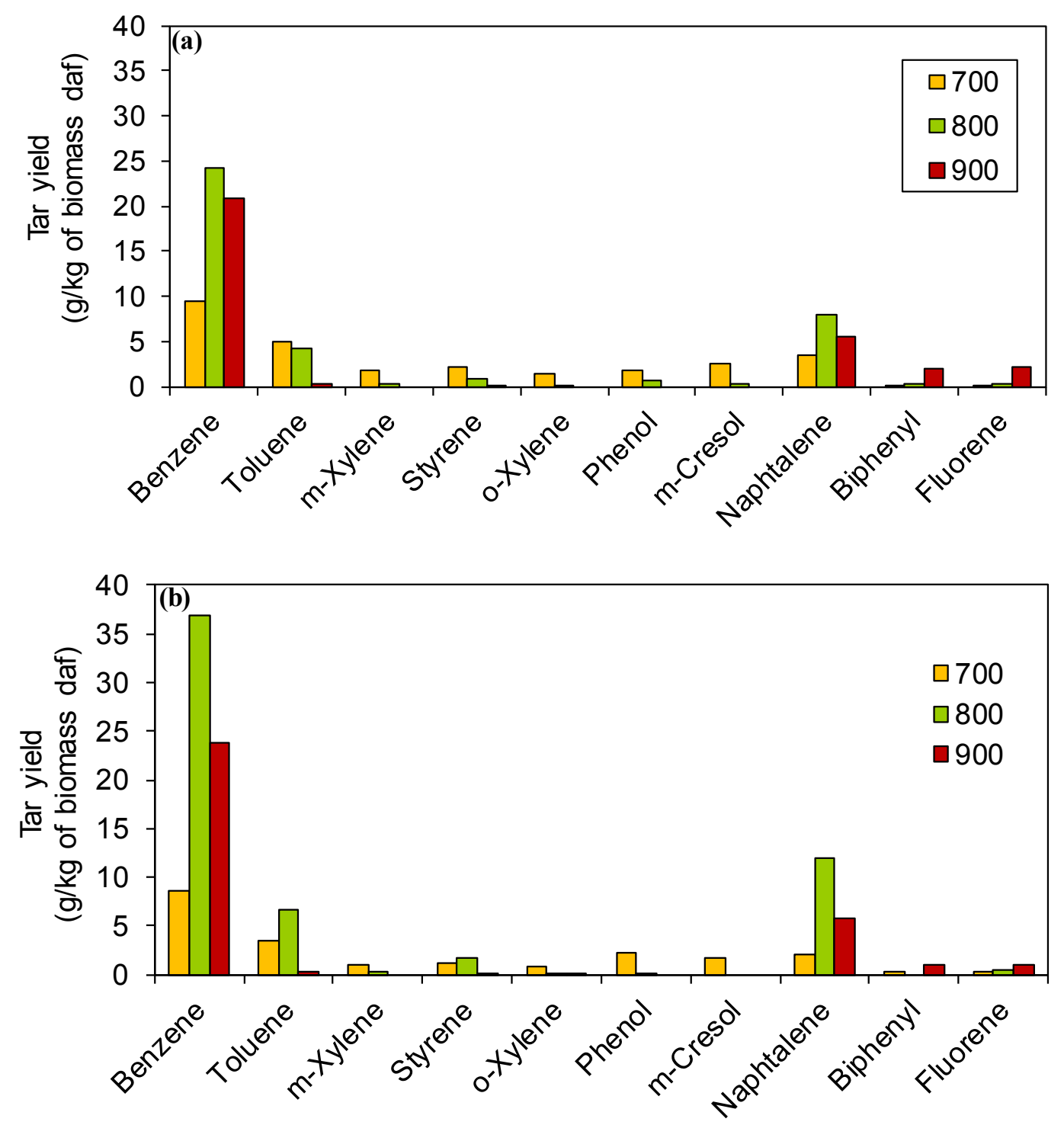

Figure 7: Green waste pellets (a) and wood pellets (b) tar species yields as a function of the reactor temperature. 


\section{Conclusion}

In this study, pyrolysis of green waste and wood was conducted in a pilot-scale rotary kiln at different temperatures: 700,800 and $900^{\circ} \mathrm{C}$. The green waste used had physicochemical properties similar to that of wood (a mixture of oak and beech). However green waste pellets contained more ash and ash composition varied from one biomass to the other. The process mass balance was established, followed by a thorough analysis and characterization of the products gas, tar and char. The pyrolysis temperature had an important effect on product yields. 80 wt. $\%$ of volatile matter (gas and bio-oil) have been produced under $800^{\circ} \mathrm{C}$. The pyrolysis temperature also impacted the gas composition. At $900^{\circ} \mathrm{C}, \mathrm{H}_{2}$ and $\mathrm{CO}$ increase to reach 36.7 and 34.5 vol. \% respectively with green waste and 35.9 and 35.3 vol. \% respectively with wood. The compositions of tars produced from both biomasses were affected by the pyrolysis conditions. Their qualitative analysis revealed the domination of light aromatics with a singlering and light polyaromatic hydrocarbons (PAHs) with 2 or 3 aromatics rings. Benzene and naphthalene were quantitatively the most important tar compounds. In addition to a high heating value exceeding $29 \mathrm{MJ} / \mathrm{kg}$, the obtained char had over 80 wt. \% of carbon content. This char can be a source of carbonaceous solid materials for other applications such as soil amendment, reducing agent in metallurgy industry, etc. The effects of high mineral content in green waste on the product yields and composition were discussed to explain some of the major discrepancies (gas yield and tar composition) between green waste and wood pyrolysis products. In future work, these results will be used to find optimal conditions for a subsequent step consisting of the steam reforming of the pyrolysis volatile matter. 


\section{Corresponding Author}

*javier.escuderosanz@mines-albi.fr, IMT Mines Albi, UMR CNRS 5302, Centre

RAPSODEE, Campus Jarlard, F-81013 Albi, cedex 09, France

\section{Acknowledgements}

The authors would like to acknowledge financial support provided by ADEME (1703C0064) and Occitanie Region (ESR_R\&F_DF-000043/2017-006713). The authors would like to thank Mr Maxime ROJAS with whom we started this research and colleagues at RAPSODEE research centre for technical help. 


\section{References}

(1) Waheed, Q. M. K.; Williams, P. T. Hydrogen Production from High Temperature Pyrolysis/Steam Reforming of Waste Biomass: Rice Husk, Sugar Cane Bagasse, and Wheat Straw. Energy \& Fuels 2013, 27 (11), 6695-6704. https://doi.org/10.1021/ef401145w.

(2) Zeng, X.; Dong, Y.; Wang, F.; Xu, P.; Shao, R.; Dong, P.; Xu, G.; Dong, L. Fluidized Bed Two-Stage Gasification Process for Clean Fuel Gas Production from Herb Residue: Fundamentals and Demonstration. Energy \& Fuels 2016, 30 (9), 7277-7283. https://doi.org/10.1021/acs.energyfuels.6b00765.

(3) Wang, N.; Chen, D.; Arena, U.; He, P. Hot Char-Catalytic Reforming of Volatiles from MSW Pyrolysis. Appl. Energy 2017, 191, 111-124. https://doi.org/10.1016/j.apenergy.2017.01.051.

(4) Wang, Y.; Namioka, T.; Yoshikawa, K. Effects of the Reforming Reagents and Fuel Species on Tar Reforming Reaction. Bioresour. Technol. 2009, 100 (24), 6610-6614. https://doi.org/10.1016/j.biortech.2009.07.026.

(5) Solar, J.; de Marco, I.; Caballero, B. M.; Lopez-Urionabarrenechea, A.; Rodriguez, N.; Agirre, I.; Adrados, A. Influence of Temperature and Residence Time in the Pyrolysis of Woody Biomass Waste in a Continuous Screw Reactor. Biomass and Bioenergy 2016, 95, 416-423. https://doi.org/10.1016/j.biombioe.2016.07.004.

(6) Di Blasi, C. Combustion and Gasification Rates of Lignocellulosic Chars. Progress in Energy and Combustion Science. 2009. https://doi.org/10.1016/j.pecs.2008.08.001.

(7) Barr, M. R.; Volpe, R.; Kandiyoti, R. Influence of Reactor Design on Product Distributions from Biomass Pyrolysis. ACS Sustain. Chem. Eng. 2019, 7 (16), 1373413745. https://doi.org/10.1021/acssuschemeng.9b01368.

(8) Neves, D.; Thunman, H.; Matos, A.; Tarelho, L.; Gómez-Barea, A. Characterization and Prediction of Biomass Pyrolysis Products. Prog. Energy Combust. Sci. 2011, 37 (5), 611-630. https://doi.org/10.1016/j.pecs.2011.01.001.

(9) Fantozzi, F.; Colantoni, S.; Bartocci, P.; Desideri, U. Rotary Kiln Slow Pyrolysis for Syngas and Char Production From Biomass and Waste-Part I: Working Envelope of the Reactor. J. Eng. Gas Turbines Power 2007, 129 (4), 901. https://doi.org/10.1115/1.2720521.

(10) Li, A. M.; Li, X. D.; Li, S. Q.; Ren, Y.; Chi, Y.; Yan, J. H.; Cen, K. F. Pyrolysis of Solid Waste in a Rotary Kiln: Influence of Final Pyrolysis Temperature on the Pyrolysis Products. J. Anal. Appl. Pyrolysis 1999, 50 (2), 149-162. https://doi.org/10.1016/S01652370(99)00025-X.

(11) Fagbemi, L.; Khezami, L.; Capart, R. Pyrolysis Products from Different Biomasses: Application to the Thermal Cracking of Tar. Appl. Energy 2001, 69 (4), 293-306. https://doi.org/10.1016/S0306-2619(01)00013-7.

(12) Dufour, A.; Girods, P.; Masson, E.; Rogaume, Y.; Zoulalian, A. Synthesis Gas Production by Biomass Pyrolysis: Effect of Reactor Temperature on Product Distribution. Int. J. Hydrogen Energy 2009, 34 (4), 1726-1734. https://doi.org/10.1016/j.ijhydene.2008.11.075.

(13) Ningbo, G.; Baoling, L.; Aimin, L.; Juanjuan, L. Continuous Pyrolysis of Pine Sawdust 
at Different Pyrolysis Temperatures and Solid Residence Times. J. Anal. Appl. Pyrolysis 2015, 114, 155-162. https://doi.org/10.1016/j.jaap.2015.05.011.

(14) De Conto, D.; Silvestre, W. P.; Baldasso, C.; Godinho, M. Performance of Rotary Kiln Reactor for the Elephant Grass Pyrolysis. Bioresour. Technol. 2016, 218, 153-160. https://doi.org/10.1016/j.biortech.2016.06.082.

(15) Kern, S.; Halwachs, M.; Kampichler, G.; Pfeifer, C.; Pröll, T.; Hofbauer, H. Rotary Kiln Pyrolysis of Straw and Fermentation Residues in a 3 MW Pilot Plant - Influence of Pyrolysis Temperature on Pyrolysis Product Performance. J. Anal. Appl. Pyrolysis 2012, 97, 1-10. https://doi.org/10.1016/j.jaap.2012.05.006.

(16) Li, A. M.; Li, X. D.; Li, S. Q.; Ren, Y.; Chi, Y.; Yan, J. H.; Cen, K. F. Pyrolysis of Solid Waste in a Rotary Kiln: Influence of Final Pyrolysis Temperature on the Pyrolysis Products. J. Anal. Appl. Pyrolysis 1999, 50 (2), 149-162. https://doi.org/10.1016/S01652370(99)00025-X.

(17) Li, A. M.; Li, X. D.; Li, S. Q.; Ren, Y.; Shang, N.; Chi, Y.; Yan, J. H.; Cen, K. F. Experimental Studies on Municipal Solid Waste Pyrolysis in a Laboratory-Scale Rotary Kiln. Energy 1999, 24 (3), 209-218. https://doi.org/10.1016/S0360-5442(98)00095-4.

(18) Kabir, M. J.; Chowdhury, A. A.; Rasul, M. G. Pyrolysis of Municipal Green Waste: A Modelling, Simulation and Experimental Analysis. Energies 2015, 8 (8), 7522-7541. https://doi.org/10.3390/en8087522.

(19) E\&E Consultant et SOLAGRO. Valorisation Des Dechets Verts En France. FranceAgriMer. May 2015, pp 1-16. https://doi.org/N ISSN 2259-0161.

(20) Prabir, B. Biomass Gasification and Pyrolysis Pratical Design; 2010; pp 27-63. https://doi.org/10.1016/B978-0-12-374988-8.00002-7.

(21) Li, S.; Xu, S.; Liu, S.; Yang, C.; Lu, Q. Fast Pyrolysis of Biomass in Free-Fall Reactor for Hydrogen-Rich Gas. Fuel Process. Technol. 2004, 85, 1201-1211. https://doi.org/10.1016/j.fuproc.2003.11.043.

(22) Phounglamcheik, A.; Babler, M. U.; Donaj, P.; Amovic, M.; Ljunggren, R.; Engvall, K. Pyrolysis of Wood in a Rotary Kiln Pyrolyzer: Modeling and Pilot Plant Trials. Energy Procedia 2017, 105, 908-913. https://doi.org/10.1016/J.EGYPRO.2017.03.413.

(23) Raveendran, K.; Ganesh, A.; Khilar, K. C. Influence of Mineral Matter on Biomass Pyrolysis Characteristics. Fuel 1995. https://doi.org/10.1016/0016-2361(95)80013-8.

(24) Collard, F. X.; Blin, J.; Bensakhria, A.; Valette, J. Influence of Impregnated Metal on the Pyrolysis Conversion of Biomass Constituents. J. Anal. Appl. Pyrolysis 2012. https://doi.org/10.1016/j.jaap.2012.02.009.

(25) Fassinou, W. F.; Van de Steene, L.; Toure, S.; Volle, G.; Girard, P. Pyrolysis of Pinus Pinaster in a Two-Stage Gasifier: Influence of Processing Parameters and Thermal Cracking of Tar. Fuel Process. Technol. 2009, 90 (1), 75-90. https://doi.org/10.1016/j.fuproc.2008.07.016.

(26) Juchelková, D.; Corsaro, A.; Hlavsová, A.; Raclavská, H. Effect of Composting on the Production of Syngas during Pyrolysis of Perennial Grasses. Fuel 2015. https://doi.org/10.1016/j.fuel.2015.03.061.

(27) Hlavsová, A.; Corsaro, A.; Raclavská, H.; Vallová, S.; Juchelková, D. The Effect of 
Feedstock Composition and Taxonomy on the Products Distribution from Pyrolysis of

Nine Herbaceous Plants. Fuel Process. Technol. 2016. https://doi.org/10.1016/j.fuproc.2015.11.022.

(28) Solar, J.; Caballero, B.; De Marco, I.; López-Urionabarrenechea, A.; Gastelu, N. Optimization of Charcoal Production Process from Woody Biomass Waste: Effect of NiContaining Catalysts on Pyrolysis Vapors. Catalysts 2018, 8 (5), 191. https://doi.org/10.3390/catal8050191.

(29) Hu, S.; Jiang, L.; Wang, Y.; Su, S.; Sun, L.; Xu, B.; He, L.; Xiang, J. Effects of Inherent Alkali and Alkaline Earth Metallic Species on Biomass Pyrolysis at Different Temperatures. Bioresour. Technol. 2015, 192, 23-30. https://doi.org/10.1016/j.biortech.2015.05.042.

(30) Zhang, W.; Henschel, T.; Söderlind, U.; Tran, K. Q.; Han, X. Thermogravimetric and Online Gas Analysis on Various Biomass Fuels. Energy Procedia 2017, 105, 162-167. https://doi.org/10.1016/j.egypro.2017.03.296.

(31) Yang, H.; Yan, R.; Chen, H.; Ho, D.; Tee, D.; Zheng, C. Pyrolysis of Palm Oil Wastes for Enhanced Production of Hydrogen Rich Gases. Fuel Process. Technol. 2006, 87, 935-942. https://doi.org/10.1016/j.fuproc.2006.07.001.

(32) Xianwen, D.; Chuangzhi, W.; Haibin, L.; Yong, C. The Fast Pyrolysis of Biomass in CFB Reactor. Energy \& Fuels 2000, $14 \quad$ (3), 552-557. https://doi.org/10.1021/ef9901645.

(33) Fahmi, R.; Bridgwater, A. V.; Darvell, L. I.; Jones, J. M.; Yates, N.; Thain, S.; Donnison, I. S. The Effect of Alkali Metals on Combustion and Pyrolysis of Lolium and Festuca Grasses, Switchgrass and Willow. Fuel 2007, 86 (10-11), 1560-1569. https://doi.org/10.1016/j.fuel.2006.11.030.

(34) Safar, M.; Lin, B.; Chen, W.; Langauer, D.; Chang, J.; Raclavska, H.; Pétrissans, A.; Rousset, P.; Pétrissans, M. Catalytic Effects of Potassium on Biomass Pyrolysis , Combustion and Torrefaction. Appl. Energy 2019, 235 (November 2018), 346-355.

(35) Harrison, D. P. Calcium Enhanced Hydrogen Production with CO2 Capture. Energy Procedia 2009, No. 1. https://doi.org/10.1016/j.egypro.2009.01.089.

(36) Song, Y.; Zhao, Y.; Hu, X.; Zhang, L.; Sun, S.; Li, C. Z. Destruction of Tar during Volatile-Char Interactions at Low Temperature. Fuel Process. Technol. 2018. https://doi.org/10.1016/j.fuproc.2017.11.023.

(37) Wang, X.; Bai, S.; Jin, Q.; Li, S.; Li, Y.; Li, Y.; Tan, H. Soot Formation during Biomass Pyrolysis : Effects of Temperature, Water- Leaching, and Gas-Phase Residence Time. J. Anal. Appl. Pyrolysis 2018, No. April, 0-1. https://doi.org/10.1016/j.jaap.2018.07.015.

(38) González, M. E.; Romero-Hermoso, L.; González, A.; Hidalgo, P.; Meier, S.; Navia, R.; Cea, M. Effects of Pyrolysis Conditions on Physicochemical Properties of Oat Hull Derived Biochar. BioResources 2017. https://doi.org/10.15376/biores.12.1.2040-2057.

(39) Li, C.; Suzuki, K. Tar Property, Analysis, Reforming Mechanism and Model for Biomass Gasification-An Overview. Renew. Sustain. Energy Rev. 2009, 13 (3), 594-604. https://doi.org/10.1016/j.rser.2008.01.009.

(40) Dufour, A.; Masson, E.; Girods, P.; Rogaume, Y.; Zoulalian, A. Evolution of Aromatic 
Tar Composition in Relation to Methane and Ethylene from Biomass PyrolysisGasification. Energy \& Fuels 2011, $25 \quad$ (9), 4182-4189. https://doi.org/10.1021/ef200846g.

(41) Morf, P. olivier. Secondary Reactions of Tar during Thermochemical Biomass Conversion. Swiss Fed. Inst. Technol. Zurich 2001, No. 14341, 1-183. https://doi.org/10.3929/ethz-a-004229756.

(42) Zhang, Z.; Pang, S. Experimental Investigation of Tar Formation and Producer Gas Composition in Biomass Steam Gasification in a $100 \mathrm{~kW}$ Dual Fluidised Bed Gasifier. Renew. Energy 2019. https://doi.org/10.1016/j.renene.2018.07.144.

(43) Jess, A. Mechanisms and Kinetics of Thermal Reactions of Aromatic Hydrocarbons From Pyrolysis of Solid Fuels. Fuel 1996, 75 (12), 1441-1448. 